Japs: Jurnal Administrasi Politik dan Sosial, Vol. 1 No 2, Agustus 2020

P_ISSN: 2722-161X e_ISSN: 2722-1601

https://japs.ejournal.unri.ac.ìd/index.php/JAPS

\title{
Implementasi Sistem Informasi Kesehatan Daerah Generik Pada Bagian Rawat Jalan di BLUD Puskesmas Rawat Inap Langgam
}

\author{
Ruslihardy \\ Program Studi Administrasi Publik, Universitas Lancang Kuning \\ Email : ruslihardy@unilak.ac.id
}

\begin{abstract}
Abstrak
Penelitian ini bertujuan untuk mengetahui implementasi sistim informasi kesehtan daerah pada bagian rawat jalan di BLUD Puskesmas rawat inap langgam. Metode penelitian menggunakan diskriptif kualitatif dengan teknik pengumpulan data observasi, wawancara dan dokumentasi. Analisis data dengan model interaktif dengan proses pengumpulan data, reduksi data, penyajian data dan penarikan kesimpulan. Hasil penelitian menunjukkan bahwa implemntasi kebijakan sistim informasi kesehatan daerah generik sudah berjalan dengan baik di BLUD puskesmas rawat inap langgam. Meski begitu masih terdapat kekurangan dalam implemntasinya seperti sarana prasarana pendukung seperti jaringan dan operator yang menjalankan masih perlu dilakukan peningkatan dan pelatihan
\end{abstract}

\section{Kata kunci : Sikda Generik, Puskesmas, Implementasi}

\begin{abstract}
This study aims to see the implementation of the regional health information system in the outpatient section of the inpatient public health center in langgam. The research method used is descriptive qualitative research with observation data observation techniques, interviews and documentation. Data analysis with an interactive model with data processing, data reduction, data presentation and data collection. The results showed that the implementation of generic regional health information system policies has been running well in inpatient public health centers in langgam. Even so, there are still deficiencies in its implementation such as supporting infrastructure such as networks and operators that are run, it still needs improvement and training
\end{abstract}

Keywords: Generic Sikda, Community Health Center, Implementation

\section{Implementasi Sistem Informasi Kesehatan Daerah Generik Pada Bagian Rawat Jalan di BLUD Puskesmas Rawat Inap Langgam}

\section{PENDAHULUAN}

Seiring dengan makin pesatnya perkembangan teknologi informasi, maka sudah mudah untuk mendapatkan informasi yang diinginkan sesuai kebutuhan kita masing-masing. Untuk mendapatkan informasi yang dibutuhkan kita bisa menggunakan elektronik yang ada. Seperti handphone, komputer, televisi dan lainnya. Hampir semua informasi yang kita butuhkan sudah di aplikasikan.

Dalam hal ini aplikasi adalah suatu program dari perangkat lunak yang berfungsi untuk memudahkan dalam mengelola dan menyimpan data yang dibuat untuk melaksanakan tugas bagi penggunanya. Data-data yang ada didalam aplikasi akan dikelolah menjadi informasi yang akurat dan dapat digunakan oleh masyarakat dan juga orang-orang yang memerlukan informasi tersebut. 
Aplikasi ini dibuat dan dirancang sesuai kebutuhan penggunanya, sehingga informasi yang diperlukan lebih akurat dan sesuai kebutuhan pengguna informasi. Aplikasi dirancang dari sebuah sistem yang terintegrasi, mebuat kita sebagai pengguna informasi lebih mudah dalam pengelolaan data yang digunakan.

Sistem merupakan gabungan beberapa elemen yang saling berhubungan untuk memudahkan aliran informasi dalam mencapai tujuan. Dari pendapat Gavinov, dkk ( 2016:35) maka ada tujuh elemen sebagai pembentuk sebuah sistem, yaitu tujuan, masukan, proses, keluaran, batas, mekanisme pengendalian dan umpan balik, dan lingkungan.Jadi semua elemen ini saling beketerkaitan satu dengan yang lainnya.

Informasi sangat penting bagi semua bidang, termasuk juga bidang kesehatan. Dalam bidang kesehatan informasi dapat digunakan sebagai pengambil suatu keputusan, membuat suatu program, mengimplementasi dan memonitoring, mengevaluasi dan menganalisa suatu keadaan dalam badan layanan kesehatan. Informasi adalah serangkaian pesan baik tertulis maupun secara lisan yang digunakan organisasi dalam pengambilan keputusan.

Tabel 1.1 Evaluasi penerapan SIKDA Generik di puskesmas yang ada di kabupaten Pelalawan

\begin{tabular}{|c|c|c|c|c|c|c|}
\hline No. & $\begin{array}{c}\text { Nama BLUD } \\
\text { Puskesmas }\end{array}$ & Loket & Pelayanan & Apotik & Gudang & $\begin{array}{r}\text { Kriteria } \\
\text { Wilayah }\end{array}$ \\
\hline 1. & $\begin{array}{l}\text { BLUD Puskesmas Rawat } \\
\text { Inap Langgam }\end{array}$ & $\checkmark$ & $x$ & $x$ & $\checkmark$ & Terpencil \\
\hline 2. & $\begin{array}{l}\text { BLUD Puskesmas } \\
\text { Kerinci }\end{array}$ & $\checkmark$ & $\checkmark$ & $x$ & $\checkmark$ & Biasa \\
\hline 3. & $\begin{array}{l}\text { BLUD Puskesmas Rawat } \\
\text { Inap Pangkalan Kuras }\end{array}$ & $\checkmark$ & $x$ & $x$ & $\checkmark$ & Biasa \\
\hline 4. & $\begin{array}{l}\text { BLUD Puskesmas Rawat } \\
\text { Inap Pangkalan Lesung }\end{array}$ & $x$ & $x$ & $x$ & $\checkmark$ & Terpencil \\
\hline 5. & $\begin{array}{l}\text { BLUD Puskesmas Rawat } \\
\text { Inap Ukui }\end{array}$ & $\checkmark$ & $\checkmark$ & $x$ & $\checkmark$ & Biasa \\
\hline 6. & $\begin{array}{l}\text { BLUD Puskesmas Rawat } \\
\text { Inap Bunut }\end{array}$ & $x$ & $x$ & $x$ & $x$ & Terpencil \\
\hline 7. & $\begin{array}{l}\text { BLUD Puskesmas } \\
\text { Pelalawan }\end{array}$ & $x$ & $x$ & $x$ & $x$ & Terpencil \\
\hline 8. & $\begin{array}{l}\text { BLUD Puskesmas Rawat } \\
\text { Inap Kuala Kampar }\end{array}$ & $x$ & $x$ & $x$ & $x$ & $\begin{array}{c}\text { Sangat } \\
\text { Terpencil }\end{array}$ \\
\hline 9. & $\begin{array}{l}\text { BLUD Puskesmas Rawat } \\
\text { Inap Kerumutan }\end{array}$ & $x$ & $x$ & $x$ & $x$ & Terpencil \\
\hline 10. & $\begin{array}{l}\text { BLUD Puskesmas Teluk } \\
\text { Meranti }\end{array}$ & $\checkmark$ & $x$ & $x$ & $\checkmark$ & $\begin{array}{c}\text { Sangat } \\
\text { Terpencil }\end{array}$ \\
\hline 11. & $\begin{array}{l}\text { BLUD Puskesmas Rawat } \\
\text { Inap Sekijang }\end{array}$ & $\checkmark$ & $x$ & $x$ & $\checkmark$ & Biasa \\
\hline $12 .$. & $\begin{array}{l}\text { BLUD Puskemsas } \\
\text { Bandar Petalangan }\end{array}$ & $x$ & $x$ & $x$ & $x$ & Terpencil \\
\hline 13. & $\begin{array}{l}\text { BLUD Puskesmas } \\
\text { Pangkalan Kuras II }\end{array}$ & $\checkmark$ & $x$ & $x$ & $\checkmark$ & Biasa \\
\hline 14. & $\begin{array}{l}\text { BLUD Puskesmas } \\
\text { Pangkalan Kerinci II }\end{array}$ & \multicolumn{4}{|c|}{ Masih dalam pengurusan } & Biasa \\
\hline
\end{tabular}

Sumber Data : Dinas kesehatan Kabupaten Pelalawan 2020

Dari data tabel diatas tanda $\checkmark$ menandakan bahwa user pada Aplikasi SIKDA Generik dilaksanakan, sedangkan $\boldsymbol{x}$ menandakan kalau usernya tidak dilaksanakan. Untuk kriteria desa kawasan puskesmas ini dapat dilihat ada 6 kriteria desa nya biasa, 6 kriteria desa terpencil dan 2 kriteria desa sangat terpencil. Sudah ada 13 Puskesmas yang menerapkan Aplikasi SIKDA Generik,tinggal 1 Puskesmas yang masih dalam pengurusan untuk menerapkan Aplikasi SIKDA Generik ini. 
Japs: Jurnal Administrasi Politik dan Sosial, Vol. 1 No 2, Agustus 2020

P ISSN: 2722-161X e ISSN: 2722-1601

https://japs.ejournal.unri.ac.id/index.php/JAPS

Penulis memilih BLUD puskesmas Langgam Sebagai tempat penelitian dengan alasan karena BLUD Puskesmas Langgam adalah faskes tingkat pertama dalam melakukan pelayanan kesehatan yang memerlukan sistem pelayanan komputerisasi sebagai penunjang pelayanan agar lebih efektif dan efisien. BLUD Puskesmas Rawat Inap Langgam termasuk dalam salah satu kawasan desa terpencil, yang berkembang sangat pesat dilihat dari menjalankan SIKDA Generiknya dibandingkan dengan Puskesmas yang berada dikawasan desa terpencil lainnya. Selain itu wilayah BLUD Puskesmas Rawat Inap Langgam saat ini merupakan perkembangan dari kawasan Tekhnopolitan.

Serta alasan penulis memilih judul tersebut sesuai dengan Peraturan Pemerintah Republik Indonesia Nomor 46 Tahun 2014 Tentang Sistem Informasi Kesehatan, Pasal 2 Pengaturan Sistem Informasi Kesehatan ini bertujuan untuk:

a. menjamin ketersediaan, kualitas, dan akses terhadap Informasi Kesehatan yang bernilai pengetahuan serta dapat dipertanggungjawabkan,

b. memberdayakan peran serta masyarakat, termasuk organisasi profesi dalam penyelenggaraan Sistem Informasi Kesehatan; dan

c. mewujudkan penyelenggaraan Sistem Informasi Kesehatan dalam ruang lingkup sistem kesehatan nasional yang berdaya guna dan berhasil guna terutama melalui penguatan kerja sama, koordinasi, integrasi, dan sinkronisasi dalam mendukung penyelenggaraan pembangunan kesehatan yang berkesinambungan.

Puskesmas adalah pelayanan tingkat pertama dalam pelayanan kesehatan. Puskesmas Langgam sebagai penyelenggara kesehatan yang wilayah kerjanya berada di kecamatan Langgam. Mempunyai misi memberi pelayanan yang bermutu dan terjangkau oleh masyarakat. Dari misi tersebut puskesmas Langgam menyediakan fasilitas layanan dan menerapkan SIKDA Generik untuk mendukung pelayanan. Tetapi dengan sudah diterapkannya SIKDA Generik, masih ditemukan pelayanan yang lambat pada pendaftaran pasien.

\section{Tabel 1.2 Data Pasien Rawat Jalan dan Rawat Inap di BLUD Puskesmas Rawat Inap Langgam.}

\begin{tabular}{|l|l|c|c|}
\hline No. & \multicolumn{1}{|c|}{ Tahun } & Jumlah Pasien Rawat Jalan & Jumlah Pasien Rawat Inap \\
\hline 1. & 2015 & 19.562 Pasien & 30 pasien \\
\hline 2. & 2016 & 17.530 Pasien & 90 pasien \\
\hline 3. & 2017 & 17.291 Pasien & 108 pasien \\
\hline 4. & 2018 & 16.965 Pasien & 99 pasien \\
\hline 5. & 2019 & 16.748 Pasien & 96 pasien \\
\hline
\end{tabular}

Sumber Data : BLUD Puskesmas Rawat Inap Langgam 2020

Dengan adanya data pada table 1.2 maka dapat dilihat bahwa perkembangan pasien yang berkunjung setiap tahunnya di puskesmas Langgam menurun disebabkan tingkat kesehatan masyarakat mulai membaik dengan adanya program-program kesehatan yang dilakukan puskesmas.Namun masih banyak pasien disetiap tahunnya seperti pada tahun 2019 ada 18.748 Pasien Dalam hal ini maka diperlukannya Sistem Informasi Kesehatan (SIK) Puskesmas yang terintegrasi guna untuk mendapatkan informasi yang lebih akurat dan lebih memudahkan pegawai dalam melaksanakan pelayanan yang efektif dan efisien. Untuk itu peneliti memfokuskan penelitian SIKDA Generik pada rawat jalan pasien bagian pendaftaran dan rekam medis pasien.

Dalam menunjang pelaksanaan SIK puskesmas yang terintegrasi maka pemerintah merancang sebuah aplikasi berbasis online yaitu Sitem Informasi Kesehatan Daerah (SIKDA) Generik. Hal ini juga sebagai pelaksanaan dari Keputusan Menteri Kesehatan Nomor 
837/Menkes/SK/VII/2007 Tentang Pengembangan Jaringan Komputer Online Sistem Informasi Kesehatan Nasional (SIKNAS Online).

Kebijakan sebagai suatu tindakan yang mengarah pada tujuan yang diusulkan oleh seseorang, kelompok atau pemerintah dalam lingkungan tertentu sehubungan dengan adanya hambatan-hambatan tertentu seraya mencari peluang-peluanguntuk mencapai tujuan atau mewujudkan sasaran yang diinginkan.

Implementasi adalah suatu tindakan atau pelaksananan rencana yang telah disusun secara cermat dan rinci guna mencapai tujuan kegiatan.Implementasi juga sebagai penyedia sarana untuk menjalankan sesuatu yang mengakibatkan dampak terhadap sesuatu implementasi sistem merupakan pelaksanaan dari sistem itu sendiri. Atau bisa juga sebagai bentuk pelaksanaan terhadap apa yang sudah dibuat untuk memanajemen suatu hal.

Untuk mendapatkan data dan informasi yang akurat maka dibutuhkannya sebuah sistem yang yang dapat mengelola data dengan baik. Dalam hal ini puskesmas Langgam melakukan pengimplementasian sebuah aplikasi sistem informasi kesehatan guna untuk memudahkan dalam pengelolaan dan pengambilan keputasan yang diperlukan.

Sistem Informasi Kesehatan (SIK) Puskesmas adalah proses pengelolaan data kesehatan menjadi informasi yang nantinya akan digunakan untuk penyusunan program dan kegiatan yang akan dilakukan di puskesmas.(gavinov dkk : 2016)

Sebelum pelaksanaan sistem berbasis online ini, maka pemerintah melakukan sosialisasi terlebih dahulu dalam menggunakan SIKDA Generik Yang akan diterapkan di puskesmas. Ini bertujuan agar tidak terjadi kesalahan dalam pelaksanaan SIKDA Generik nantinya.

\section{Gambar 1.1. Alur Implementasi Aplikasi SIKDA Generik}

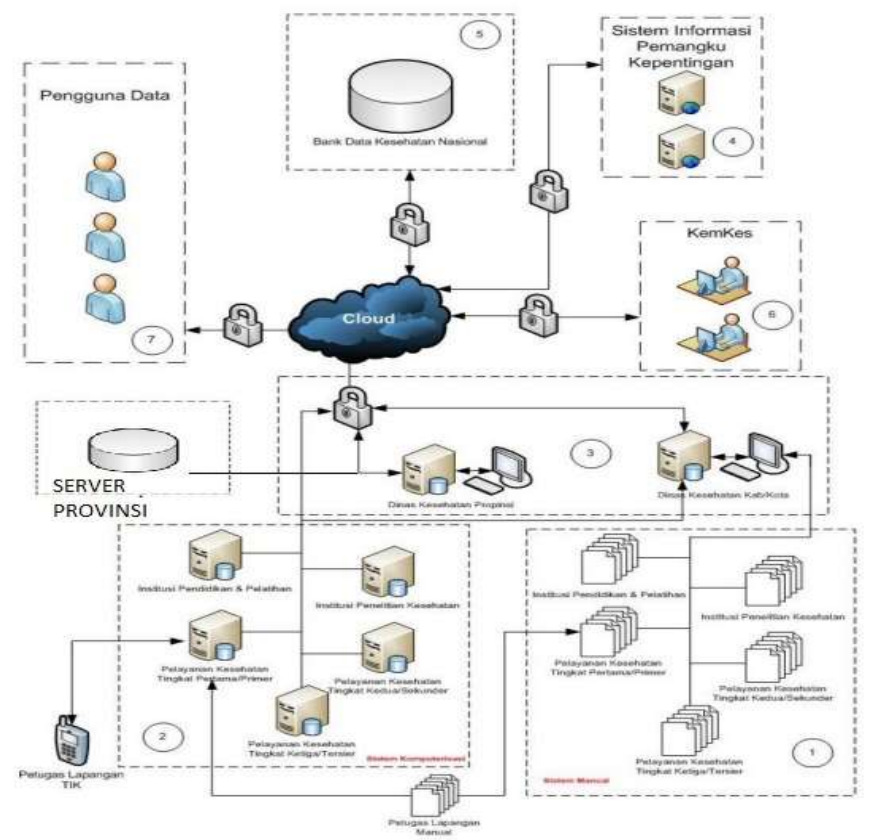

Sumber Data : BLUD Puskesmas Rawat Inap Langgam, 2020

Dari Gambar diatas dapat dilihat alur dari implementasi aplikasi SIKDA Generik, yang mana sudah terintegrasi langsung dengan Dinas Kesehatan Kabupaten/Kota, Dinas Kesehatan Provinsi, Kementrian Kesehatan, dan juga pengguna data yang bisa sudah terhubung dengan SIKDA Generik dengan secara online.

SIKDA Generik adalah aplikasi sistem informasi kesehatan daerah yang berlaku secara nasional yang menghubungkan secara online dan terintegrasi seluruh puskesmas, 
rumah sakit, dan sarana kesehatan lainnya, baik itu milik pemerintah maupun swasta, dinas kesehatan kabupaten/kota, dinas kesehatan provinsi dan kementrian kesehatan.

Tujuan dari implementasi SIKDA Generik ini, yaitu :

1. Meningkatkan layanan kesehatan di puskesmas melalui sistem informasi yang tepat sehingga pelayanan kesehatan sesuai dengan kebutuhan masyarakat

2. Untuk menyeragamkan proses komunikasi data dan informasi kesehatan secara online dan terintegrasi antara seluruh puskesmas

3. Menerapkan standarisasi Sistem Informasi kesehatan, sehingga dapat tersedianya data dan informasi kesehatan yang akurat, tepat dan cepat dengan mendayaguanakan tekhnologi informasi dan komunikasi.

SIKDA Generik ini sangat membantu dalam mengelola data dan penyimpanan data pasien yang berkujung dipuskesmas karena Aplikasi SIKDA Generik ini bisa menyimpan data semua pasien yang menggunakan kartu asuransi kesehatan maupu pasien umum. Sehingga tidak ada lagi tumpang tindih data dan kehilangan data pasien yang akan berkunjung berobat ulang.

Untuk pasien yang menggunakan kartu asuransi kesehatan BPJS juga bisa diinput di SIKDA Generik ini, karena SIKDA Generik ini sudah tersambung(Bridging) dengan Aplikasi Pcare BPJS. Sehingga untuk pelayanan pasien BPJS tidak perlu lagi membuka Aplikasi Pcare BPJS. Dan memudahkan petugas dalam melakukan pelayanan.

\section{Bagan 1.1 Alur Kunjungan Pasien Rawat Jalan di BLUD Puskesmas Rawat Inap} Langgam

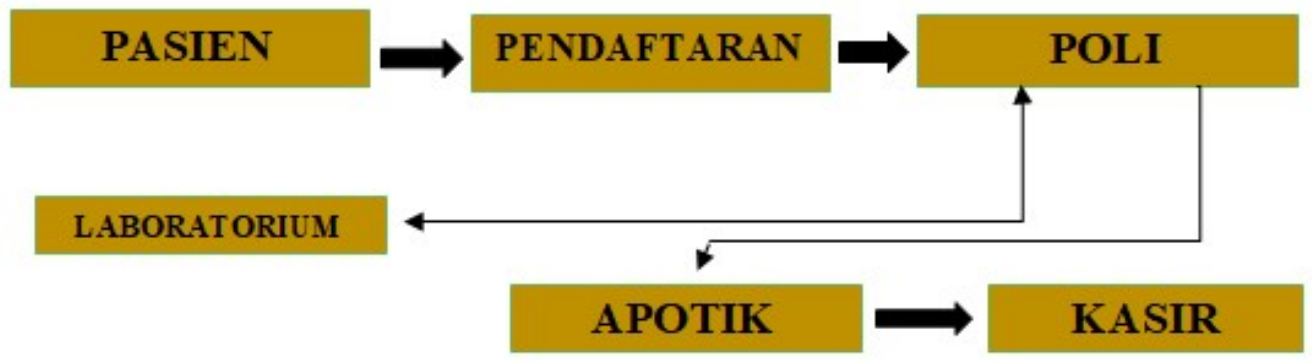

Sumber Data: BLUD Puskesmas Rawat Inap Langgam 2020

Dari bagan diatas bisa dilihat bagaimana alur pasien rawat jalan datang berkunjung kepuskesmas, dengan keterangan yaitu :

- Pasien datang berkunjung kepuskesmas dengan mengambil antrian untuk pelayanan di loket/pendaftaran,

- Setelah melakukan pendaftaran pasien akan menunggu pelayanan di depan poli pelayanan yang akan ditujuhnya,guna untuk mendapat pelayanan sesuai yang keluhan pasien.Dipoli pasien akan mendapatkan resep obat atau saran untuk pemeriksaan Laboratorium dari dokter.

- Pasien yang mendapatkan saran kelaboratorium akan diperiksa oleh analis guna untuk pemeriksaan dokter selanjutnya.

- Setelah mendapat pelayanan di poli maka pasien akan mendapatkan resep obat untuk ditebus ke apotik,pasien akan mendapatkan obat sesuai yang diresepkan dokter.

- Lalu pasien akan diarahkan oleh petugas apotik ke kasir untuk menyelesaikan administrasi dan pembayaran setelah pengobatan.

\section{Bagan 1.2 Alur proses pelayanan rawat jalan pasien di dalam SIKDAGenerik}




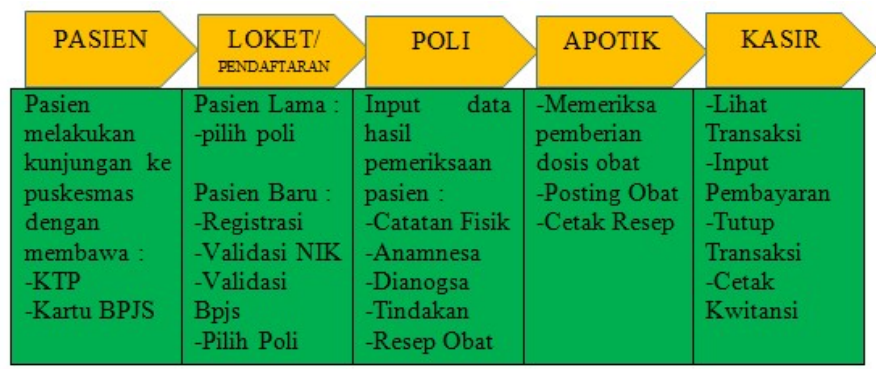

Dari pemaparan tentang alur peyanan rawat jalan pasien di BLUD Puskesmas Rawat Inap Langgam diatas, alur proses pelayanan rawat jalan didalam SIKDA Generik tidaklah jauh berbeda, hanya untuk pemeriksaan laboratoriumnya sudah termasuk kedalam pelayanan poli.

Dalam pengoperasian SIKDA Generik ini ada lima role untuk SIKDA Generik ini, yaitu :

a. Gudang Puskesmas, Login sebagai gudang puskesmas memiliki hak akses untuk menginput transaksi masuk dan keluar obat,

b. Loket, login sebagai loket memiliki hak akses untuk memproses pendaftaran pasien yang akan melakukan kunjungan dipuskesmas,

c. Pelayanan, login sebagai pelayanan yang digunakan oleh pasien. Disini akan diinput dianogsa pasien, resep obat dan kasir

d. Apotik, Login sebagai apotik yaitu memproses cetak resep dan pemberian obat pada resep dari pelayanan dan juga juga untuk menginput obat dan vaksin yang dikirim dari gudang puskesmas.

e. Kasir, login sebagai kasir bertugas memproses pembayaran obat dan tindakan yang diinputkan pelayanan

f. Admin/All, login sebagai admin memiliki hak akses untuk semua fungsi yang ada di Aplikasi SIKDA Generik. Admin juga akan melakukan setting aplikasi dan dapat juga menambah user login sesui role yang diinginkan.

Tabel 1.3 Perbedaan menggunakan sistem manual dan Aplikasi SIKDA Generik di BLUD Puskesmas Rawat inap Langgam

\begin{tabular}{cll}
\hline No. & \multicolumn{1}{c}{ Sistem Manual } & \multicolumn{1}{c}{ Apikasi SIKDA Generik } \\
\hline 1. & $\begin{array}{l}\text { Sering terjadi kehilangan rekam medis } \\
\text { pasien karena penyimpanan data } \\
\text { manual }\end{array}$ & $\begin{array}{l}\text { Data kunjungan rekam medis pasien } \\
\text { yang hilang bisa dilihat lagi pada }\end{array}$ \\
2. & $\begin{array}{l}\text { Banyak terjadi tumpang tindih pada } \\
\text { data pasien }\end{array}$ & $\begin{array}{l}\text { Aplikasi } \\
\text { Tidak ada lagi terjadi tumpang tindih } \\
\text { data pasien }\end{array}$ \\
3. & Lama untuk menyusun dan mengambil \\
keputusan dalam pelapaoran & $\begin{array}{l}\text { Data untuk pelaporan sudah } \\
\text { terekap/tersistem sehingga }\end{array}$ \\
& & memudahkan dalam mengambil \\
& keputusan dalam pelaporan
\end{tabular}

Sumber Data : BLUD Puskesmas Rawat Inap Langgam 2020

SIKDA Generik ini sangat membantu pegawai puskesmas dalam pekerjaan. Tidak hanya dalam pengumpulan data yang akurat dan cepat, tetapi juga membantu dalam pekerjaan di pelayanan. Dibandingkan dengan sistem manual yang terkadang harus membutuhkan waktu lama dalam pencatatan untuk pelayanan. Tetapi dalam hal ini petugas masih menggunakan buku register kunjungan untuk pencatatan kunjungan pasien, walaupun sudah didaftarkan pasien pada SIKDA Generik.

Keunggulan SIKDA Generik ini selain membantu puskesmas juga Dinas Kesehatan Provinsi bisa melakukan analisis multy variable dari data base SIKDA Generik adalah data individu danpengawasan terhadap kinerka puskesmas yang ada diwilayah kerjanya dengan 
memperhatikan pelayanan kesehatan dan program yang dilaksanakan di puskesmas secara harian, mingguan, bulanan dan tahuanan.

Tabel 1.4 Data Kinerja BLUD Puskesmas Rawat Inap Langgam

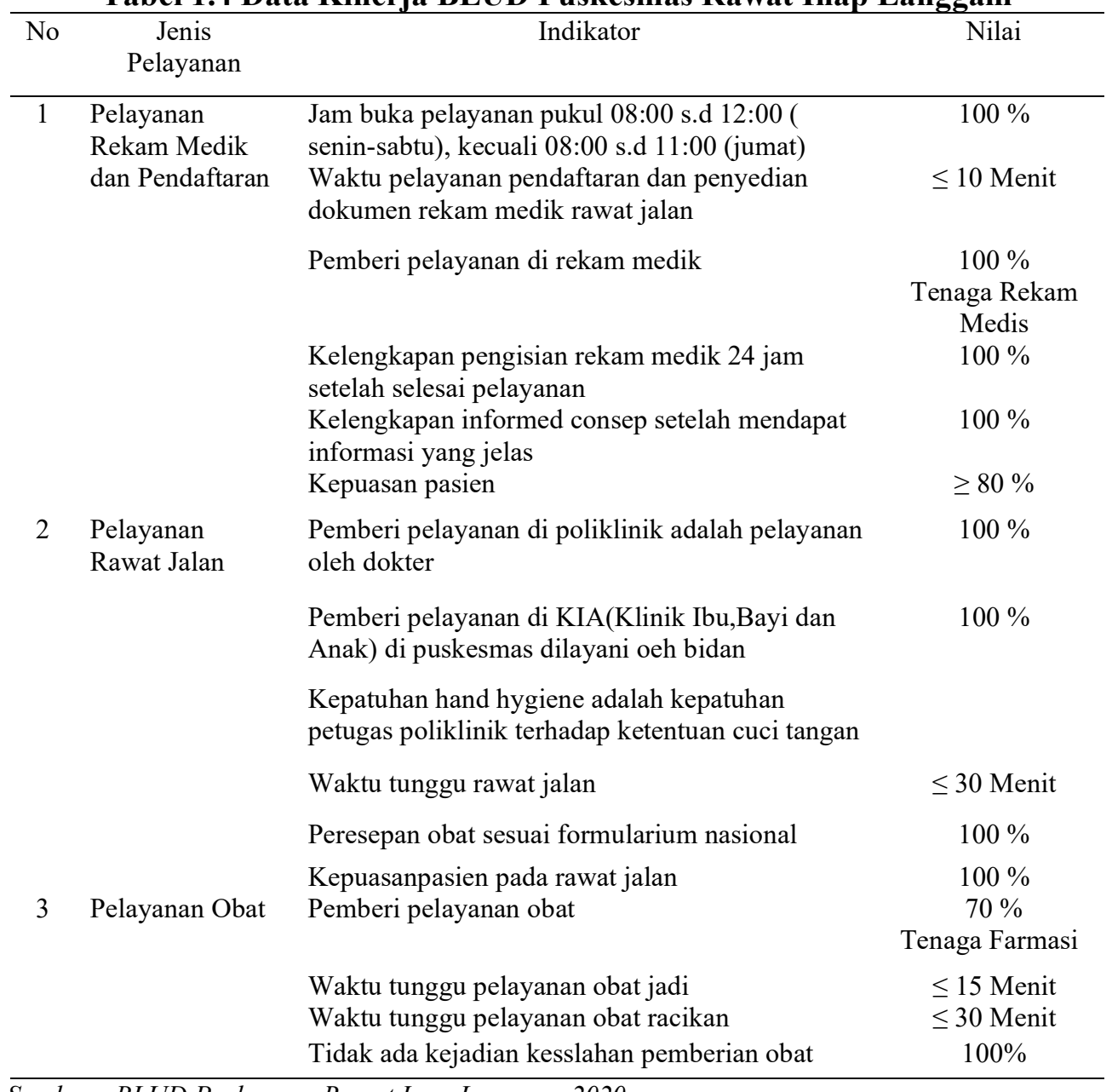

Sumber : BLUD Puskesmas Rawat Inap Langgam 2020

Berdasarkan standar opreasional prosedur dalam penggunaan SIKDA Generik diatas setiap kegiatan ditentukan jumlah waktu untuk memproses pelayanan. Seperti pelayanan pendaftaran dan rekam medis pasien membutuhkan waktu 10 menit per pasien.

Dengan menggunakan SIKDA Generik ini seharusnya tidak ada lagi pasien yang menunggu lama di ruang tunggu pasien, data pasien sudah terinput otomatis di SIKDA Generik dan petugas tidak memerlukan waktu lama untuk pelayanan pasien. Tetap keadaannya masih ada pasien yang menunggu di bangku tunggu pasien.

Dari tabel 1.5 dapat dilihat bahwasanya pendidikan rata-rata operator role SIKDA Generik di BLUD Puskesmas Rawat Inap Langgam berasal dari pendidikan kesehatan . Sehingga pengetahuan dan kompetensi dalam penggunaan SIKDA Generik masih rendah, Sering terjadi kelambatan dalam melakukan pelayanan. Sementara untuk menjalankan 
Japs: Jurnal Administrasi Politik dan Sosial, Vol. 1 No 2, Agustus 2020

P ISSN: 2722-161X e ISSN: 2722-1601

https://japs.ejournal.unri.ac.ìd/index.php/JAPS

SIKDA Generik ini dibutuhkan operator yang mempunyai tamatan dari pendidikan komputer untuk menunjang kelancaran dalam penggunaan aplikasi.

Tabel 1.5 Data Operator Role Aplikasi SIKDA Generik

\begin{tabular}{clcl}
\hline NO. & $\begin{array}{c}\text { Operator Aplikasi SIKDA Generik di } \\
\text { BLUD Puskesmas Rawat Inap Langgam }\end{array}$ & Pendidikan & Umur \\
\hline 1. & Operator Admin & D3 Kebidanan & 26 Tahun \\
2 & Operator Gudang Obat & D3 Farmasi & 32 Tahun \\
3. & Operator Loket/Pendaftaran & SMK Pertanian & 28 Tahun \\
4. & Operator Poli Umum & S1 Keperawatan & 26 Tahun \\
5. & Operator Poli Gigi & D3 Keperawatan & 30 Tahun \\
6. & Operator Poli Ibu & D3 Kebidanan & 46 Tahun \\
7. & Operator Poli Anak & D3 Keperawatan & 45 Tahun \\
8. & Operator Poli KB & D4 Kebidanan & 31 Tahun \\
\hline
\end{tabular}

Sumber : BLUD Puskesmas Rawat Inap Langgam 2020

Pada saat proses pendaftaran dan rekam medis dilakukan, sering ditemukan gangguan pada SIKDA Generik. Seperti gangguan aplikasi dan kerusakan jaringan pada saat penginputan dan penyimpanan data pasien umum dan pasien BPJS. Operator langsung menyampaikan keluhan yang terjadi pada aplikasi yang khusus dibuat untuk tempat menyampaikan keluhan operator saat pengoperasian SIKDA Generik. Tetapi karena lambannya pembimbing program dalam menanggapi keluhan maka operator melakukan pendaftaran dan rekam medis pasien secara manual.

Alur komunikasi dari Kementrian Kesehatan ke puskesmas melalui dua instansi dalam struktur organisasi pelaksana sangat jauh, tetapi disini komunikasi dilakukan secara langsung yaitu implementator menyampaikan langsung keluhan kepada implementor. Tetapi kenyataannya masih terjadi kelambatan tanggapan dari implementor.

Dari pengamatan penulis dilapangan, maka ditemukan beberapa gejala/fenomena yaitu Masih kurangnya pengetahuan dan kompetensi SDM dalam menjalankan SIKDA Generik pada pelayanan pendaftaran dan rekam medis pasien masih membutuhkan waktu yang cukup lama. Selanjutnya lambannya penanganan Dinas Kesehatan Provinsi Riau dalam menanggapi keluhan dari operator SIKDA Generik.

\section{METODE PENELITIAN}

Pada penelitian ini penulis menggunakan metode penelitian deskriptif kualitatif. Metode penelitian deskriftif kualitatif merupakan metode yang menggunakan analisis, proses dan makna. Dan landasan teori dimanfaatkan sebagai pemandu agar penulis lebih fokus penelitian sesuai dengan fakta yang ada dilapangan. Analisis data yang digunakan adalah metode deskriptif kualitatif, yaitu metode yang menganalisis dan menggambarkan kondisi apa adanya, tanpa memberi perlakuan manipulasi pada variabel yang diteliti dengan proses memperoleh data bersifat apa adanya. Data-data yang telah diperoleh dengan menganalisisnya sesuai kondisi yang terjadi dilapangan diolah untuk menjadi hasil penelitian dan kemudian mengambil kesimpulan.

\section{HASIL DAN PEMBAHASAN}

Implementasi adalah suatu penerapan atau pelaksanaan dari sebuah rencana yang telah disusun secara matang dan terperinci guna mencapai tujuan yang ingin dicapai. Implementasi SIKDA Generik ini dilakukan pemerintah agar mendapatkan informasi dan data yang akurat dan membantu sistem pelayanan puskesmas yang efektif dan efisien .

BLUD Puskesmas Rawat Inap Langgam menggunakan SIKDA Generik ini mulai dari tahun 2017. Dengan adanya SIKDA Generik ini sangat membantu pegawai dalam pelayanan dan pelaporan BLUD Puskesmas Langgam. 
Japs: Jurnal Administrasi Politik dan Sosial, Vol. 1 No 2, Agustus 2020

P ISSN: 2722-161X e ISSN: 2722-1601

https://japs.ejournal.unri.ac.ìd/index.php/JAPS

\section{Komunikasi}

Komunikasi adalah penyampaian pesan oleh seseorang atau komunikator kepada komunikan atau penerima pesan baik secara langsung maupun tidak langsung. Komunikasi sangat penting untuk kelancaran jalannya suatu kebijakan atau program yang telah dibuat.

Dengan adanya komunikasi yang lancar antara pembuat kebijakan dengan implementor maka akan membantu kelancaran dalam penerapan Aplikasi SIKDA Generik di BLUD Puskesmas Rawat Inap Langgam, karena untuk penerapan suatu kebijakan yang telah dibuat tidak hanya cukup dengan beberapa kali komunikasi. sosialisasi program SIKDA Generik sudah dilakukan pada tahun 2017, yaitu dengan mengundang 2 perwakilan dari puskesmas untuk mengikuti sosialisasi penggunaan SIKDA Generik di provinsi. Kemudian perwakilan tersebut tergabung dalam grup whatsapp SIKDA Kabupaten sebagai wadah komunikasi selanjutnya. Tetapi disini hanya 2 perwakilan saja yang terpapar sosialisasi dan ikut pelatihan tentang implementasi SIKDA Generik.

\section{Sumber Daya}

Kemampuan implementor dapat diukur dari tingkat pendidikan, tingkat pemahaman terhadap tujuan dan sasaran serta aplikasi detail program dan bagaimana kemampuan pengarah dalam menyampaikan program dan mengarahkan. operator SIKDA Generik di BLUD Puskesmas Rawat Inap Langgam tidak memiliki tenaga khusus untuk menjalankan SIKDA Generik ini. Pimpinan BLUD Puskesmas Rawat Inap Langgam memberdayakan tenaga yang ada saja. Rata-rata tingkat pendidikannya yaitu tenaga kesehatan, ada juga pendidikannya tamatan Sekolah Menengah Atas (SMA). Dan kemampuan operator untuk menggunakan komputer pun masih cukup lemah. Dalam segi anggaran dalam implementasi SIKDA Generik ini sudah baik karena untuk pemasangan jaringan internetnya itu sudah ditanggung langsung oleh Dinas Kabupaten Pelalawan, sedangkan BLUD Puskesmas Rawat Inap Langgam tinggal menyediakan dana untuk pengisian kuota tiap bulannya. Dan komputer sebagai penunjang jalannya Program SIKDA Generik ini pun sudah tercukupi.

\section{Disposisi}

Disposisi adalah menunjukkan karakteristik yang menempel erat kepada implementor kebijakan/program. Karakter yang paling penting dimiliki implementor adalah kejujuran, komitmen dan demokratis. Apabila implementor mempunyai karakter tersebut maka program akan terlaksana dengan baik.

Kejujuran akan mengarahkan implementor untuk tetap berada dalam jalur program/kebijakan. Komitmen dan kejujuran membawanya semakin antusias dalam melaksanakan tahap-tahap program secara konsisten. Sikap demokratis akan meningkatkan kesan baik implementor dan kebijakan di hadapan anggota kelompok sasaran. pelimpahan wewenang dalam melaksanakan implementasi SIKDA Generik ini, Dinas Kesehatan Provinsi Riau sudah memberikan wewenang langsung kepada pelaksana yang ada di BLUD Puskesmas Rawat Inap Langgam dalam mengelolah data pada aplikasi. Tentunya sesuai dengan pedoman yang telah diberikan oleh Dinas Kesehatan Provinsi Riau.

\section{Struktur Birokrasi}

Struktur Birokrasi adalah struktur atau tatanan organisasi, bagan, pembagian kerja dan hierarki yang terdapat pada sebuah lembaga yang penting untuk menjalankan tugas-tugas agar lebih teratur.Dalam hal penelitian ini yang menjadi struktur birokrasinya adalah struktur implementasi kebijakan program SIKDA Generik.

Ketersediaan SOP Yang Mudah Dipahami Standar Operasional Prosedur dalam implementasi SIKDA Generik di BLUD Puskesmas Langgam dibagian pendaftaran sudah dimiliki SOP yang ada itu berbentuk tutorial setiap role yang ada pada SIKDA Generik 
Japs: Jurnal Administrasi Politik dan Sosial, Vol. 1 No 2, Agustus 2020

P ISSN: 2722-161X e ISSN: 2722-1601

https://japs.ejournal.unri.ac.id/index.php/JAPS

tersebut. dalam menggunakan SIKDA Generik sesuai dengan Standar Operasional Prosedurnya. Untuk SOP SIKDA Generik sudah tersedia dan mudah dipahami dan dimengerti oleh operator yang menjalankan Aplikasi ini.

\section{Hambatan yang mempengaruhi Implementasi SIKDA Generik di BLUD Puskesmas Rawat Inap Langgam}

Untuk menjalankan SIKDA Generik ini juga dibutuhkan SDM yang berkompeten agar tujuan dari program SIKDA Generik ini bisa tercapai. Namun ada beberapa faktor penghambat dalam pelasanaan program implementasi SIKDA Generik antara lain :

\section{Jaringan yang tidak lancar dan aplikasi jarang diperbaharui}

Dalam Implementasi SIKDA Generik perlu sarana yang mendukung seperti jaringan yang lancar, sehingga untuk pengoperasian aplikasi tidak terjadi kendala. Dan pada aplikasi juga perlu dilakukan pembaharuan supaya tidak terjadi masalah pada memproses data. Contohnya pada pengoperasian aplikasi sering muncul "error" saat menyimpanan data dikarenakan aplikasi masih menggunakan fitur-fitur lama.

\section{Kurangnya Pelatihan dan Pendidikan Pada SDM Sebagai Petugas Operator SIKDA Generik.}

Pengoperasian SIKDA Generik dibutuhkan pelatihan dan bimbingan khusus untuk operator SIKDA Generik dan tentunya pelatihan dan bimbingan seharusnya dilakukan secara rutin. Dengan adanya pelatihan maka akan membantu petugas operator lebih memahami tentang tujuan pengimplementasian SIKDA Generik dan fitur-fitur yang ada pada aplikasi.

\section{KESIMPULAN}

Dari hasil penelitian tentang Implementasi SIKDA Generik di BLUD Puskesmas Langgam dapat dijelaskan bahwa Implementasi SIKDA Generik mencakup komunikasi, sumber daya, disposisi dan struktur birokrasi Dengan terpenuhi semua indikator maka implementasi SIKDA Generik akan terlaksana dengan baik sesuai tujuan. Implementasi SIKDA Generik di BLUD Puskesmas Rawat Inap Langgam sudah berjalan cukup baik. Dengan didapatkannya hasil penelitian dari empat indikator (1) Komunikasi : Sosialisasi dilakukan dan intensitas komunikasi tidak dilakukan secara terus menerus.(2) Sumber Daya : SDM tidak ada yang berpendidikan khusus, pemahaman tentang tujuan implementasi SIKDA Generik masih kurang. Anggaran tercukupi untuk mendukung implementasi SIKDA Generik.(3) Disposisi : pelaksana kebijakan mendukung dan menerima dengan sangat baik implementasi SIKDA Generik.(4) Struktur Birokrasi : SOP mudah dipahami dan strukrur organisasi rentannya sangat jauh tetapi tidak menghambat komunikasi

\section{DAFTAR PUSTAKA}

Fs, H. T. (2018). Pelaksanaan Asas Pelayanan Publik Pada Puskesmas Simpang Baru Kota Pekanbaru. Jurnal Niara, 10(2).

Isnawati, K. (2016). Implementasi Aplikasi Sistem Informasi Kesehatan Daerah (Sikda) Generik Di Upt. Puskesmas Gambut Kabupaten Banjar. Journal Of Information Systems For Public Health, 1(1), 64-71.

Miles, M. B. Huberman (1995): Qualitative Data Analysis. A Source Book For New Methods

Rian, N. (2009). Public Policy, Formulasi, Implementasi, Dan Evaluasi Pt. Elex Media K Omputindo, Jakarta.

Saputra, T., Marlinda, P., \& Sufi, W. Implementasi Kebijakan Inovasi Pelayanan Publik Di Puskesmas Jaya Mukti Dalam Meningkatkan Kepuasan Masyarakat. Jurnal Niara, 11(2.2019), 177-188. 
Japs: Jurnal Administrasi Politik dan Sosial, Vol. 1 No 2, Agustus 2020

P ISSN: 2722-161X e ISSN: 2722-1601

https://japs.ejournal.unri.ac.id/index.php/JAPS

Saputra, T., \& Marlinda, P. (2018). Services Innovation Of Sikda Optima Program At Puskesmas Jaya Mukti Dumai City (No. 5wcgv). Center For Open Science.

Sahit, R. Teknik Analisis Data Penelitian Kualitatif Model Mile Dan Huberman.

Suwitri, S. (2008). Konsep Dasar Kebijakan Publik. Semarang: Badan Penerbit Universitas Diponegoro.

Tahir, A. (2014). Kebijakan Publik Dan Transparansi Penyelenggaraan Pemerintahan Daerah. Penerbit Alfabeta.

Utami, B. C. (2020). Inovasi Pelayanan Publik Di Desa Seberang Taluk Kabupaten Kuantan Singingi. Jurnal Niara, 13(1), 237-244.

Wibawa, S. (1994). Kebijakan publik. Proses dan Analisis, Intermedia, Jakarta.. 